\title{
Oral Processing, Satiation and Obesity: Overview and Hypotheses
}

\author{
Arnold Slyper \\ Pediatric Endocrinology, Clalit Health \\ Services, Jerusalem, Israel
}

\begin{abstract}
Increasing the speed of eating or decreasing the amount of chewing of a test meal significantly decreases its satiation, increases concomitant caloric intake, and influences entero-endocrine secretion. Speed of eating is a strong risk factor for obesity and longitudinal studies suggest an etiological relationship. Individuals with obesity have an increase in bite size, less chewing per bite, decreased satiation, and greater food intake. Oral processing in terms of bite size and amount of chewing per gram of food is influenced by food texture and textural complexity. Soft foods increase bite size and decrease chewing per gram of food and meal duration compared to hard foods. An ultra-processed diet can lead to greater weight gain than a non-processed diet and a significant increase in eating rate. Many children with obesity are noted by their parents to have persistent hunger on a questionnaire and this is often extreme. Results of attempts to change eating behavior have been mixed in terms of producing long-term changes in eating behavior and body weight. It is hypothesized that there may be a unidirectional relationship between changes in oral processing, satiation and weight gain. However, the presence of persistent hunger can produce a vicious cycle that may exacerbate obesity and make treatment difficult. The increased energy density of foods as found particularly in ultra-processed foods also influences energy intake and obesity.

Keywords: obesity, eating behavior, nutrition, satiation
\end{abstract}

\section{Introduction}

The prevalence of obesity continues to increase throughout the world. It has been estimated from 1990 to 2010 data that by 2030 the number of individuals with obesity or overweight will have increased from 1.33 to 3.28 billion, or about onethird of the projected global population. ${ }^{1}$ Moreover, it is not only obesity that is increasing but also morbid obesity. ${ }^{2,3}$

The treatment and prevention of obesity is traditionally focused on controlling energy intake. However, the long-term success of this approach at an individual and global level is disappointing. This suggests that a fresh look is needed at to how obesity arises, how it perpetuates itself, and how it can be prevented and treated.

The aim of this review is to examine paradigms for the development of obesity based on a number of hypotheses regarding satiation and oral processing. Satiation can be defined as the state that leads to meal termination and is a determinant of meal size, whereas satiety is the state whereby further eating is inhibited by fullness until the next meal. Oral processing relates to processes that take place in the mouth during the eating of food, and the focus of this review will be particularly on the mechanical events biting and chewing. The hypotheses that will be reviewed are: 1 . Global obesity and much individual obesity are due to decreased satiation; 2.
Correspondence: Arnold Slyper

Pediatric Endocrinology, Clalit Health

Services, Jerusalem, Israel

Tel +972585788844

Email arnoldslyper@yahoo.com 
A decrease in satiation can arise as a result of changes in oral processing, such as an increased bite size, increased speed of eating and less chews per bite; 3 . Foods that are easily orally processed are more likely to lead to a decrease in satiation; 4. Disturbances in satiation lead to an increase in energy intake; and 5. Obesity may be accompanied by persistent hunger.

The literature on oral processing is considerable and the intention of this article is not to review all papers published on this topic but rather to present an overview pertaining specifically to the hypotheses presented. Articles were located by PubMed by subject heading and through secondary references. Particular attention was given to meta-analyses. Six areas related to aspects of oral processing are reviewed, and each section ends with a summary. These summary paragraphs contain personal opinions and should be regarded as points for discussion and possibly for further research. In the Conclusion section, the observations from these six sections are combined to produce an overall hypothesis to explain how much individual and global obesity arises and perpetuates itself.

\section{The Techniques Used to Assess Satiation and Oral Processing}

A number of methods have been used to quantitate satiation during test meals. One method is the use of analogue scales from 0 to 100 that are completed by the subject during a feeding experiment. Another method, frequently used in addition, is to assess food intake during the test meal itself if this is an ad libitum test meal or during a second ad libitum meal administered after the test meal. An analysis by Sadoul et $\mathrm{al}^{4}$ found that appetite scales significantly predict subsequent energy intake following a test meal, although in this type of setting the correlation is of low magnitude.

A number of physiological processes within the mouth are involved in dealing with food. These include in humans an initial bite or sip, a chewing sequence for each mouthful of food, salivation and lubrication of the food bolus to make it suitable for swallowing, enzymatic activity on the food ingested, sensations within the mouth arising from the food, and finally swallowing of the bolus. The mechanical processes of biting and chewing have been extensively studied and will be the focus of this review.

Eating behavior can be assessed in a relatively simple way by means of a self-rating of usual speed of eating.
Another party, such as a family member can also do this assessment. Time taken for consuming a standard test meal can also be evaluated. Meal microstructure in terms of bites and chews can be assessed using videography, and more recently by wearable sensors. ${ }^{5}$ These two techniques enable a detailed assessment of bites, individual chews and pauses between chewing sequences.

The disappearance of food from a portable weighing scale connected to a computer enables the generation of a graph displaying food removal from the plate, and this can be synchronized with the sensor or videography. Knowledge of the amount of food eaten during a test meal enables calculation of the bite rate and chewing rate expressed as number of bites or chews per gram of food.

Eating behavior studied by videotaping has been shown to display excellent intra-individual consistency for 146 healthy male and female individuals across four meals for measures of ad libitum intake, eating rate, and oral processing in terms of bite size, oral exposure time per bite, and chews per $g$ of food for the same or similar test meals eaten over four non-consecutive days. ${ }^{6}$ Chewing rate per unit of time was shown to be relatively constant for 35 different foods in 15 subjects and averaged approximately 1 chew/second. ${ }^{7}$

Most eating studies have been performed in the laboratory rather than in the field because of the instrumentation involved. A question posed by Doulah et $\mathrm{al}^{8}$ was whether eating behavior in the field is identical to that in the laboratory. They therefore compared oral processing of self-selected meals eaten in isolation or eaten in a social setting where participants could move, eat and interact without restriction (although still in a laboratory) by means of video observation and a wearable food intake sensor. Meal duration in the field-like study was significantly higher for breakfast and dinner compared to the laboratory setting, presumably because of social interactions. It was suggested that eating behavior should preferably be studied in the field. Nevertheless, this is a counsel of perfection that is technically difficult to do.

Differences have been noted between men and women for oral processing. Zijlstra et $\mathrm{al}^{9}$ found that ad libitum intake and eating rate for a test meal are significantly higher in men than in women. Hill et $\mathrm{al}^{10}$ showed that women take significantly more bites than men, although their bites are smaller. Thus, despite biting more, they take longer to eat and eat less food per second. A higher initial eating rate in males was noted by Kissileff et al. ${ }^{11}$ Others 
have found that energy intake is greater in males than females; in men of normal weight because they eat longer and in males with obesity because they eat faster. ${ }^{12}$ Men may also order more second helpings. ${ }^{13}$

\section{The Influence of Eating Behavior on Satiation and Entero-Endocrine Secretion}

Recognition of the primacy of the oral route in eliciting satiation comes from a number of studies showing that food consumed by mouth leads to much greater suppression of hunger ratings and desire to eat than when food is infused directly into the stomach or small intestine. ${ }^{14-16}$ Nevertheless, a combination of oral, gastric and intestinal factors is necessary for optimal expression of fullness and satiety. Cecil et al, ${ }^{14}$ for example, found that a sense of fullness, and conversely an inverse relationship to hunger and desire to eat, was directly related to gastric content and was sensed when gastric fullness was at its maximum.

A meta-analysis by Robinson et $\mathrm{al}^{17}$ that included 22 studies in 4 subgroups was unable to find a significant relationship between eating rate and hunger at the end of a meal for up to 3.5 hours after a meal despite showing a significant influence of speed of eating on energy intake. However, a meta-analysis of 42 studies by Krop et $\mathrm{al}^{18}$ focusing specifically on short-term satiation and in which there was an intervention that either directly or indirectly affected oral processing characteristics such as number of chews, eating rate and texture manipulation and in which the comparison involved two extreme conditions, showed that short-term satiation measured by subsequent food intake and/or ratings for hunger or desire to eat were both significantly influenced by oral processing parameters such as eating rate, oral residence time and number of chews. Krop et $\mathrm{al}^{18}$ ascribe their variant results from those of Robinson et $\mathrm{al}^{17}$ to their including more oral processing variables and their inclusion of more studies. A meta-analysis by Miquel-Kergoat et al ${ }^{19}$ of 13 trials that examined the effect of chewing also found that prolonged mastication significantly reduced self-reported hunger $(\mathrm{p}<0.001$ ), with 5 of 16 studies showing a significant effect on self-reported visual analogue scales for satiation or satiety and 10 of 16 experiments showing that increased chewing reduced subsequent food intake.

Of interest are a number of studies showing that manipulating eating behavior by changing the total time or number of chews with which a test meal is eaten is associated with changes in entero-endocrine secretion. Hormones secreted by the gut with an anorexic effect include cholecystokinin (CKK), peptide YY (PYY), glucose-dependent insulinotropic hormone gastric inhibitory peptide (also known as gastric inhibitory peptide or GIP), and glucagon-like peptide- 1 (GLP-1). ${ }^{20}$ In brief, CCK is secreted by I-cells mainly in the duodenum and jejunum and effects meal size or early stage satiation. PYY is released from the ileum and colon and it inhibits gastric mobility and gastric emptying and reduces appetite. GLP-1 is secreted by L-cells found throughout the intestinal tract and is an incretin promoting insulin secretion in a glucosedependent manner. It also inhibits gastric emptying and mobility and has an anorexic effect. Blood levels of CCK, GLP-1 and PYY are low during fasting and increase in response to a meal. The entero-endocrine hormone ghrelin acts in opposition to these anorexigenic hormones by increasing premeal hunger and initiating eating. It is produced especially in the stomach and activates cells in the brain centers. Levels of this hormone increase during fasting and decrease after a meal.

Studies that have examined postprandial enteroendocrine secretion are summarized in Table $1 .^{21-27}$ It can be concluded from all these studies that decreasing the speed of eating of a test meal or increasing the number of chews by which it is eaten is associated with decreased hunger ratings during that meal and/or decreased energy intake for that meal or at a subsequent meal when the test meal is fixed, these being indicators of increased satiation or increased between-meal satiety. Oral processing in terms of chewing is not the sole factor controlling satiation, and other aspects of bowel function may be operative, but oral processing appears to be the most influential.

The observation that the number of chews by which a meal is eaten also influences entero-endocrine secretion, with an increase in the secretion of the anorexic hormones GLP-1 and PYY and decrease in the secretion of the orexigenic hormone ghrelin in many, although not all studies in which this has been tested, provides additional support for a significant role for mastication in appetite control. Some of the GLP-1 response may be indirect, in that increased chewing may lead to a greater breakdown of carbohydrate, which in turn could lead to increased postprandial glucose levels and thus increased levels of the incretin GLP-1. ${ }^{23}$ Moreover, based on the timing of the post-prandial secretion of these hormones extending over several hours, it is unclear how much of a role these 
Table I Postprandial Hormone Levels as a Function of Eating or Chewing Fast or Slow

\begin{tabular}{|c|c|c|c|}
\hline Study & Subjects & Food Cue and Exposure & Effect on Hunger and Hormone Levels \\
\hline $\begin{array}{l}\text { Kokkinos } \\
\text { et } \mathrm{al}^{21}\end{array}$ & $\begin{array}{l}\text { I7 healthy adult } \\
\text { males }\end{array}$ & $\begin{array}{l}300 \mathrm{~mL} \text { of ice cream eaten over } 5 \mathrm{~min} \text { (fast) } \\
\text { versus } 30 \mathrm{~min} \text { (slow) }\end{array}$ & $\begin{array}{l}\text { Higher PP curve for PYY and GLP-I for slow versus fast eating. } \\
\text { No difference in ghrelin }\end{array}$ \\
\hline $\begin{array}{l}\text { Rigamonti } \\
\text { et } \mathrm{al}^{22}\end{array}$ & $\begin{array}{l}\text { I8 adolescents } \\
\text { and adults with } \\
\text { obesity }\end{array}$ & $\begin{array}{l}10 \mathrm{kcal} / \mathrm{Kg} \text { of ice cream eaten over } 5 \mathrm{~min} \text { (fast) } \\
\text { versus } 30 \text { minutes (slow) }\end{array}$ & $\begin{array}{l}\text { No stimulation of PP GLP-I with fast-eating, whereas slow } \\
\text { eating increased PP GLP-I only in adolescents. Slow eating } \\
\text { stimulated greater PP PYY in adolescents than adults. }\end{array}$ \\
\hline $\mathrm{Li}$ et $\mathrm{al}^{22}$ & $\begin{array}{l}16 \text { lean and } 14 \\
\text { young men with } \\
\text { obesity }\end{array}$ & $\begin{array}{l}\text { Ad libitum pork pie eaten with as much } \\
\text { chewing or as little chewing as possible ( } 40 \mathrm{vs} \\
\text { I5 chews/ } 10 \mathrm{gm} \text { bite) }\end{array}$ & $\begin{array}{l}\text { Fast chewers had less energy intake, higher PP GLP-I and CCK } \\
\text { and lower PP ghrelin in the lean and subjects with obesity. }\end{array}$ \\
\hline Zhu et $\mathrm{al}^{23}$ & $\begin{array}{l}21 \text { healthy } \\
\text { males }\end{array}$ & $\begin{array}{l}\text { Fixed amount of pizza chewed } 15 \text { times (slow) } \\
\text { or } 40 \text { times (fast) }\end{array}$ & $\begin{array}{l}\text { Lower ratings for hunger and higher PP glucose, insulin, GIP } \\
\text { and CKK after fast chewing }\end{array}$ \\
\hline $\begin{array}{l}\text { Cassady } \\
\text { et } \mathrm{al}^{24}\end{array}$ & $\begin{array}{l}13 \text { healthy } \\
\text { adults }\end{array}$ & $55 \mathrm{~g}$ of almonds chewed 10,25 or 40 times & $\begin{array}{l}\text { Higher suppression of hunger after } 40 \text { than } 10 \text { chews and } \\
\text { higher PP GLP-I after } 40 \text { than } 25 \text { chews }\end{array}$ \\
\hline $\begin{array}{l}\text { Hawton } \\
\text { et } \mathrm{al}^{25}\end{array}$ & $\begin{array}{l}21 \text { normal- } \\
\text { weight adults }\end{array}$ & $\begin{array}{l}600 \mathrm{kcal} \text { meal eaten over } 24 \text { minutes (normal) } \\
\text { or } 6 \text { minutes (fast) }\end{array}$ & $\begin{array}{l}\text { Greater 2-hour fullness and less energy from snacks with } \\
\text { normal eating with greater PP ghrelin suppression, and greater } \\
\text { PP PYY from baseline }\end{array}$ \\
\hline $\begin{array}{l}\text { Alsalim } \\
\text { et } \mathrm{al}^{26}\end{array}$ & $\begin{array}{l}24 \text { healthy } \\
\text { adults }\end{array}$ & $\begin{array}{l}524 \text { Kcals solid breakfast eaten over } 5 \text { minutes } \\
\text { (fast) or } 12 \text { minutes (slow) }\end{array}$ & No difference in PP glucose, insulin, GLP-I and GIP \\
\hline $\begin{array}{l}\text { Shah } \\
\text { et } \mathrm{al}^{27}\end{array}$ & $\begin{array}{l}25 \text { men and } \\
\text { women }\end{array}$ & $\begin{array}{l}\text { Breakfast eaten over } 10 \text { min (fast) or } 30 \\
\text { minutes (slow) }\end{array}$ & $\begin{array}{l}\text { No difference in hunger, fullness and PP ghrelin, GLP-I and } \\
\text { PYY }\end{array}$ \\
\hline
\end{tabular}

Abbreviation: pp, postprandial.

hormonal responses have in the control of satiation, since it could be argued that a more immediate stimulus would be required such as provided by neural signaling. It may be speculated, therefore, that the influence of enteroendocrine hormones is more on inter-meal satiety or even persistent hunger (see later section). Hence, the processes involved in the link between oral processing and satiation are still very much open to elucidation.

\section{Eating Behavior, Energy Intake and Body Weight}

The previous section has shown that satiation can be influenced by changes in oral processing, including rate of mastication and speed of eating. It is logical to postulate, therefore, that an increase in speed of eating could lead to an increase in energy intake since the physiological brake of satiation on excessive food intake is compromised. This section discusses the evidence that there is indeed a strong positive relationship between eating speed and energy intake. Also, that increased speed of eating is a common feature of obesity, and that an increased speed of eating bears a strong positive relationship to indices of obesity both in cross-sectional and longitudinal studies. The relationships between other aspects of oral processing and energy intake and energy expenditure will also be reviewed.

That a significant relationship exists between eating speed and energy intake is apparent from the meta-analysis of 22 studies by Robinson et al mentioned in the previous section. ${ }^{17}$ In the studies analyzed, subjects were of any age, eating rate was manipulated and the effect of doing this on concurrent energy intake, self-reported hunger, or both were observed. Subgroup analysis indicated that the effect on energy intake was unrelated as to how the change in speed of eating was achieved, which could have been instructions to chew slowly and take more time to eat, manipulating food form, computerized feedback, changing the method of food delivery by using a spoon instead of a straw, or using a container for liquid that refilled slowly or quickly.

The association between self-reported speed of eating and indices of obesity in adults was the subject of a systemic review and meta-analysis by Ohkuma et $\mathrm{al}^{28}$ that included 12 cross-sectional and 3 longitudinal studies. Mean difference in BMI between individuals eating quickly and those eating slowly was $1.78 \mathrm{Kg} / \mathrm{m}^{2}$, and the pooled odds ratio for the presence of obesity from eating quickly was 2.15 (95\% confidence interval 1.84-2.51). A more recent cross-sectional 
study from New Zealand (and which was not therefore included in Ohkuma's meta-analysis) of 1589 women aged 40-50 years and in which speed of eating was self-assessed on a 5-point scale found that BMI increased by $2.8 \%(\mathrm{p}<0.001)$ for each category increase in self-reported speed of eating. ${ }^{29}$

Several large pediatric studies, particularly from Asia, and therefore also not included in Ohkuma's meta-analysis because of the subjects' age, found eating speed to be significantly associated with BMI (Table 2):

Two longitudinal studies included in Okhuma's metaanalysis and worthy of mention are that of Yamane et $\mathrm{al}^{38}$ of 1396 first year Japanese university students who found that the odds ratio of becoming overweight was 4.40 (2.228.75 ) for those who ate quickly using a 4-point self-reported questionnaire performed at baseline and at 3-year follow-up. Also, a study of 529 male Japanese office workers who were self-reported fast eaters or medium/slow eaters that found that fast eaters had significantly greater weight gain on 8-year follow-up ( $1.9 \mathrm{Kg}$ versus $0.7 \mathrm{Kg}, \mathrm{p}=0.008) .{ }^{39}$

A more objective assessment of eating behavior performed in 84 female Japanese college students using video recordings found that the total number of chews and total meal duration eating a salmon rice ball were negatively correlated with $\%$ fat, BMI, and circumference of the waist, abdomen and hip $(\mathrm{p}<0.05){ }^{40}$ A simultaneous subjective eating speed assessment using a 3-point scale found that body mass, $\%$ fat, BMI, and circumferences were greater in the fast-eating group than in the slow-eating group (all $p<$ 0.05 ). Other objective cross-sectional studies in adults and children have similarly found an association between BMI and eating rate and speed of eating. ${ }^{41,42}$

A number of studies have compared eating rate, bite size and chewing rate in normal weight and individuals with obesity. Already in 1975 , Wagner et $\mathrm{al}^{43}$ had noted

Table 2 Cross-Sectional and Longitudinal Pediatric Studies Relating Speed of Eating to Obesity or Overweight

\begin{tabular}{|c|c|c|c|c|}
\hline Study & $\begin{array}{l}\text { Type of } \\
\text { Study }\end{array}$ & Subjects & Procedure & Results \\
\hline Liu et $\mathrm{al}^{30}$ & $\begin{array}{l}\text { Cross- } \\
\text { sectional }\end{array}$ & $\begin{array}{l}\text { II } 23 \text { pre-school Chinese } \\
\text { children }\end{array}$ & $\begin{array}{l}\text { 3-point scale for speed of } \\
\text { eating }\end{array}$ & $\begin{array}{l}\text { Fast eating increased adjusted odds ratio for } \\
\text { overweight of } 1.92(1.3 \mid-2.80) \text { and for obesity } 1.37 \\
(1.0-1.88)\end{array}$ \\
\hline Lin et $\mathrm{a}^{31}$ & $\begin{array}{l}\text { Cross- } \\
\text { sectional }\end{array}$ & $\begin{array}{l}\text { II } 38 \text { preschool Chinese } \\
\text { children }\end{array}$ & $\begin{array}{l}\text { Observation of lunch } \\
\text { duration }\end{array}$ & $\begin{array}{l}\text { Each } 5 \text {-minute increase in meal duration decreased } \\
\text { likelihood for obesity by } 0.86 \mathrm{I} \text {. Adjusted odd ratio } \\
0.970 \text { for overweight for meal duration }\end{array}$ \\
\hline $\begin{array}{l}\text { Zhang } \\
\text { et } \mathrm{al}^{32}\end{array}$ & $\begin{array}{l}\text { Cross- } \\
\text { sectional }\end{array}$ & 767 7-12-year-old students & $\begin{array}{l}\text { 2-point scale for speed of } \\
\text { eating }\end{array}$ & Odds ratio for obesity of $3.18(2.28-4.44)$ \\
\hline $\begin{array}{l}\text { Zeng } \\
\text { et } \mathrm{al}^{33}\end{array}$ & $\begin{array}{l}\text { Cross- } \\
\text { sectional }\end{array}$ & $\begin{array}{l}50,037 \text { 7-17-year-old } \\
\text { Chinese children }\end{array}$ & $\begin{array}{l}\text { 3-point scale for speed of } \\
\text { eating }\end{array}$ & $\begin{array}{l}\text { Fast eating odds ratio for obesity of }|.5|-|.6| \\
\text { compared to medium speed of eating }\end{array}$ \\
\hline $\begin{array}{l}\text { Ochiai } \\
\text { et } \mathrm{al}^{34}\end{array}$ & $\begin{array}{l}\text { Cross- } \\
\text { sectional }\end{array}$ & $\begin{array}{l}3256 \text { I2-13-year-old male } \\
\text { and female Japanese } \\
\text { adolescents }\end{array}$ & $\begin{array}{l}3 \text {-point scale for speed of } \\
\text { eating and } 2 \text {-point scale for } \\
\text { eating until full (yes or no) }\end{array}$ & $\begin{array}{l}\text { Increased adjusted odds ratio for overweight in boys } \\
\text { with fast eating compared to medium, and in those } \\
\text { eating until full compared to not eating until full } 2.78 \\
(1.76-4.38) \text {. Fast eating in girls led to a significant } \\
\text { increase in odds ratio but only in those eating until full }\end{array}$ \\
\hline $\begin{array}{l}\text { Ochiai } \\
\text { et } \mathrm{al}^{35}\end{array}$ & Longitudinal & $\begin{array}{l}427 \text { Japanese schoolgirls } \\
\text { aged 9-10 years who were } \\
\text { non-overweight and obese }\end{array}$ & $\begin{array}{l}\text { 2-point scale for speed of } \\
\text { eating and followed for } 3 \\
\text { years }\end{array}$ & $\begin{array}{l}\text { Differences in BMI, \% body fat, waist circumference } \\
\text { and waist to height ratio increased only in those who } \\
\text { ate quickly }\end{array}$ \\
\hline $\begin{array}{l}\text { Yamagishi } \\
\text { et } \mathrm{al}^{36}\end{array}$ & Longitudinal & $\begin{array}{l}1490 \text { boys and girls aged } 3 \\
\text { years who returned } \\
\text { questionnaires at } 6 \text { and } 12 \\
\text { years }\end{array}$ & $\begin{array}{l}\text { 4-point scale for speed of } \\
\text { eating at } 6 \text { and } 12 \text { years }\end{array}$ & $\begin{array}{l}\text { Children with increased speed of eating had higher } \\
\text { BMI than those who never increased speed of eating: } \\
20 \mathrm{vs} 17.9 \text { for boys and } 20 \mathrm{vs} 18.4 \mathrm{~kg} / \mathrm{m}^{2} \text { for girls }\end{array}$ \\
\hline $\begin{array}{l}\text { Ochiai } \\
\text { et } \mathrm{al}^{37}\end{array}$ & Longitudinal & $\begin{array}{l}934 \text { non-overweight } \\
\text { Japanese children age 9-10 } \\
\text { years }\end{array}$ & $\begin{array}{l}\text { 3-year follow-up using } \\
\text { a } 3 \text {-point scale for speed of } \\
\text { eating }\end{array}$ & $\begin{array}{l}\text { Eating quickly associated with relative risk for } \\
\text { becoming overweight } 3.65(1.52-8.76)\end{array}$ \\
\hline
\end{tabular}

Note: The brackets contain the $95 \%$ confidence intervals. 
that compared to adults who were not obese, males and females with obesity spend less time-consuming their meals and chew each mouthful of food for a shorter amount of time. Zijlstra et $\mathrm{al}^{9}$ matched 27 normal-weight adults to an equal number of those overweight and obese and studied their ad libitum intake of spiced rice and apple pie yogurt eaten from bowls with a spoon. Food intake was measured by hidden electronic scales during videotaped test sessions. Mean bite size for spiced rice was significantly larger in the group that were obese and overweight, but no other significant differences in eating behavior were noted such as initial eating rate, eating deceleration rate, ad libitum intake, meal duration, number of bites or eating rate. Laessle et $\mathrm{al}^{13}$ investigated 49 adults with obesity and 47 normal-weight adults in a laboratory setting with a universal eating monitor that provided cumulative intake curves and found that the volunteers with obesity had a higher initial eating rate, ate larger spoonfuls, and had a greater total intake for an ad libitum serving of chocolate pudding, but no differences were found for rate of deceleration and duration of intake. A study of 162 college students with obesity and nonobese controls presented with high and low preference doughnuts of fixed weight found that eating rate (amount eaten per second) increased as obesity increased due to a larger bite size and bite speed (time per bite). ${ }^{10}$ McCrickerd et $\mathrm{al}^{6}$ studied 146 male and female adults using video recording and a universal eating monitor and found that adults who ate faster took larger bites and consistently consumed more energy independent of sex, body composition and reported appetite. Mattfield et al ${ }^{44}$ measured bite size by a table embedded scale in 271 participants who could select any meal they liked from a cafeteria and also found that the volunteers with obesity took larger bites than normal and overweight individuals $(\mathrm{p}=0.002$ and $\mathrm{p}=0.017$ respectively).

Controlled experiments in normal adults have also demonstrated the importance of bite size in determining energy intake, with a number of studies showing an increase in ad libitum intake when bite or sip size is increased. ${ }^{45,46}$ Children with faster eating also have larger bite size and increased energy intake as a consequence of this. ${ }^{47}$ Goto et al ${ }^{48}$ showed in young Japanese women that with increasing mouthful volume of different solid foods, the total number of chews increases, but their chewing rate (chews per weight of food) decreases.

A longitudinal study by Berkowitz et al ${ }^{49}$ videotaped basal feeding behavior in 61 children at age 4 years who were considered at high or low risk for obesity because of maternal BMI. At age 6, an increased risk of becoming overweight or obese was predicted by greater maternal BMI, the child's mouthfuls of food / $\mathrm{min}$, and total caloric intake/min during a test meal. Regression analysis indicated that only mouthfuls of food/min positively predicted changes in BMI from 4 to 6 years, and mouthfuls of food/ min and gender predicted changes in sum of skinfolds and total body fat measured by dual-energy X-ray absorptiometry, with the girls showing greater fat mass. They conclude that a rapid eating style, characterized by increased mouthfuls of food/min, may be a behavioral marker for the development of childhood obesity.

There is evidence of a hereditable component to children's eating rates. Eating rates in terms of bites/min were video recorded in 254 twin children aged 10 to 12 years while eating ad libitum sandwich quarters and fruit salad at home. ${ }^{50}$ Children were categorized into 3 groups, obese and overweight, higher normal weight, and lower normal weight, and a significant linear association across the three weight groups was found for eating rate $(\mathrm{p}=0.01)$. Regression analyses showed that eating rate increased by $0.18 \mathrm{bites} / \mathrm{min}$ for each 1-unit increase in BMI SD score. The calculated hereditability of eating rate was high at 0.62 (95\% CI 0.45, 0.74).

Another aspect of speed of eating is its association with energy expenditure. Normal components of energy expenditure are basal energy expenditure, the thermic effect of food, and activity thermogenesis, with the thermic effect of food accounting for approximately $10 \%$ of total energy expenditure. Toyoma et $\mathrm{al}^{51}$ demonstrated that the thermal effect of food for a 15-minute period from the start of eating was significantly lower in 9 young women who were not obese eating a meal quickly over 5 minutes compared with eating it with a regular speed over 15 minutes $(\mathrm{p}<0.01)$. Changes in autonomic nervous activity at rest and after the start of eating were also measured using spectral analysis of heart rate, and based on the changes detected it was suggested that the decreased mastication of fast-eating decreases sympathetic nervous activity. This observation is supported by another mastication study in 17 normal young women that found that the energy expenditure of mastication from chewing hard, tasteless non-caloric gum in 7 subjects was quite small at $3.7 \pm 0.8 \mathrm{~kJ}$ for the 20 minutes. However, 30 chews per mouthful of a solid meal eaten for 20 minutes by 10 subjects produced a significantly higher thermic effect over 3 hours than swallowing the same pureed meal 
eaten without chewing $(134.2 \pm 15.5$ vs $67.8 \pm 13.8 \mathrm{~kJ} / 3$ hours, $\mathrm{p}=<0.001$ ) as well leading to increased satiety $(\mathrm{p}=0.005) .{ }^{52}$ Another study reported that masticationinduced thermogenesis from 12 minutes of chewing a large amount of non-nutritional gum was $11 \mathrm{kcal} / \mathrm{h} .{ }^{53}$ Brondel et $\mathrm{al}^{54}$ found that the increase in energy expenditure in response to a four-course meal was approximately halved when a test meal was given as an infusion into the stomach $(+5.7 \%)$ than when ingested orally $(+12 \%)$. Also, that even sensory stimulation from sight, smell and taste without chewing significantly increased energy expenditure $(+3.2 \%)$. Energy expenditure was measured over a 20 minute rest period and then for $110 \mathrm{~min}$. Despite these studies, the question as to whether obesity is accompanied by a decreased thermic effect of food is a controversial one and there are studies both supporting and negating this hypothesis. ${ }^{55,56}$

In sum, many studies in normal volunteers have demonstrated that in an ad libitum meal situation, an increased speed of eating leads to an increase in caloric intake. There is also considerable evidence that many adults and children with obesity have an increased speed of eating and that fast eating is a strong risk factor for obesity. Longitudinal studies indicate a possible etiological relationship between speed of eating and increased weight gain and obesity in adults and children. The heritability of speed of eating may be one link in the genetic predisposition to obesity. The increased speed of eating seen in individuals with obesity is associated with an increase in bite size and speed of biting, and an increase in bite size may be an important abnormality in those tending to overweight or obesity. An increased bite size leads to less oral processing as a result of a decrease in chewing per bite, and therefore less satiation and greater food intake. A change in the thermic effect of food as a result of mastication and non-masticatory stimuli may be a significant phenomenon, although its influence on body weight is still unclear and if present it is probably small.

\section{The Influence of Food Texture and Ultra-Processed Foods on Eating Behavior and Body Weight}

Many aspects of a food influence how much of it will be eaten, including sensory influences provided by visual cues, its odor, taste intensity, texture and palatability, and even anticipation of its satiating effect. ${ }^{57}$ Food texture, in particular, has been shown to exert considerable influence on eating behavior. Food texture reflects its firmness, crunchiness, smoothness, creaminess and thickness. ${ }^{57}$

The influence of texture on speed of eating and energy intake is very apparent when comparing liquid, semi-solid and solid foods. ${ }^{58}, 500 \mathrm{~g}$ of apple juice, for example, can be consumed within 1.5 minutes compared to 7 minutes for $500 \mathrm{~g}$ of apples. ${ }^{58} \mathrm{In}$ an unrestricted real-life setting, ad libitum intakes in grams of a semi-liquid and semi-solid milk-based product were $14 \%$ and $39 \%$ lower than for a chocolate-flavored liquid $(p=<0.0001$ for both differences). ${ }^{59}$ Texture also has a strong influence on eating behavior for solids foods. Soft foods that can be easily eaten, in contradistinction to harder foods, lead to an increase in bite size, decreased chewing rate per gram of food, decreased oro-sensory exposure per gram of food, and increased energy intake. ${ }^{58,60,61}$

Bolhuis et $\mathrm{al}^{62}$ compared eating dynamics in 50 subjects for four meals - a rice salad served with either raw or boiled vegetables and a hamburger with either hard or soft bread. The meal containing harder foods was associated with a $13 \%$ lower energy intake $(p<0.001)$, smaller bites, more chewing per gram of food, and a longer oral duration per gram of food $(p<0.05)$. Even small changes in food texture can influence eating rate. Decreasing the particle size of granola added to yogurt from $12 \mathrm{~mm}$ to $6 \mathrm{~mm}$ at a constant weight concentration during ad libitum intake increased the number of chews per spoon and decreased spoon size, eating rate and ad libitum intake without affecting liking. ${ }^{63}$ The difference in eating rate and ad libitum intake between yogurts containing small and large granola particles was $5 \mathrm{~g} / \mathrm{min}(7 \%)(\mathrm{p}<0.0001)$ and $17 \mathrm{~g}(5 \%)$ respectively $(\mathrm{p}=0.003)$.

Larsen et $\mathrm{al}^{64}$ found that textural complexity also influences satiation, this being defined as "the number and dynamic progression of individual textures perceived from the first bite, through mastication, to the point of swallow." These investigators provided a starter model food of either high or low textural complexity, but matched for flavor, energy density, and oral processing time, in a gelatin-agar gel mixture with different layered and particulate inclusions to 31 volunteers and showed decreased ad libitum food intake during a subsequent twocourse meal when it was proceeded by the starter of high complexity.

The effect of taste intensity on oral processing is variable. Salty and sour taste intensity do appear to influence eating rate, while sweetness or bitterness intensity do not. $^{61,65} \mathrm{~A}$ recent cross-over study of 4 gel-based 
isocaloric model foods that differed in texture (soft or hard) and had low or high-intensity sweetness were consumed until satiation in 58 normal-weight volunteers. ${ }^{61}$ Compared to the hard model foods, the soft-textured foods were associated with a lower number of chews (10.1 vs $26.9, \mathrm{p}<0.001)$, higher eating rate $(26.3$ versus $15.3 \mathrm{~g} / \mathrm{min}, \mathrm{p}><0.001)$, and $21.5 \%$ higher intake $(\mathrm{p}<$ 0.001 ), whereas sweetness had no effect. That food texture has a greater influence on eating behavior than taste intensity has been noted by other investigators. ${ }^{60,65}$

To explore the possibility of devising a diet composed of foods with a lower energy density and requiring more time to eat, van den Boer et $\mathrm{al}^{66}$ assessed eating rate and energy intake rate (Kcal/min) for 240 commonly eaten Dutch foods. Large variations in eating rate were found, with liquids and semi-solids being most responsible for this. As might have been anticipated, eating rate was lower when food texture was more solid and harder. Accordingly, hard solids were mainly present in the lower eating rate quartiles and semi-solids and liquids mainly in the upper eating rate quartiles. Eating rate was inversely associated with energy density and fiber content and positively associated with water content. Salty and sour taste intensities were positively correlated with eating rate, but not sweet or bitter tastes. Interestingly, eating rate for foods recommended to the public by the Netherlands Nutrition Center were not significantly different from nonrecommended foods, even after liquids were excluded from the data set.

The only extensive information available on the influence of diets on eating behavior is for diets high in ultraprocessed foods. Monteiro and colleagues have devised a scheme for differentiating ultra-processed foods from other foods and their so-called NOVA classification has been acknowledged by organizations such as the Pan American Health Organization of WHO, the Food and Agriculture Organization of the UN, and dietary guidelines for Brazil. ${ }^{67,68}$ This system divides foods into four categories - unprocessed or minimally processed foods, processed culinary ingredients (such as oils, butter, sugar and salt), processed foods (such as bottled vegetables, canned fish, freshly made bread), and ultra-processed foods. Ultraprocessed foods are defined as

formulations of several ingredients which besides salt, sugar, oils and fats, include food substances not used in culinary preparations, in particular flavors, colors, sweeteners, emulsifiers and other additives used to imitate sensorial qualities of unprocessed or minimally processed foods and their culinary preparations or to disguise undesirable qualities of the final product. ${ }^{67,68}$

Soft drinks, packaged snacks, reconstituted meat products, and pre-prepared meat products are included in this category. This system is highly focused on food additives, which are not known to influence eating behavior. Nevertheless, the presence of these additives may coincidentally identify foods that are easily processed orally because they have undergone heavy factory processing. Many of them are high in their sugar and fat content. However, this definition has not been used in all studies related to ultra-processed foods making comparisons between studies difficult.

Using Monteiro's definition and data from the National Health and Nutrition Examination Survey 2009-2010, ultra-processed foods were found to constitute $57.9 \%$ of energy intake in the US and to contribute $89.7 \%$ of the energy intake from all added sugars. ${ }^{67}$ Use of ultraprocessed foods has been increasing throughout the world because of their convenient properties. They can be prepared cheaply in bulk, they have a long shelf life for transport and display, and they do not decay rapidly in the home. Because they are already semi-prepared, they can be easily and quickly used in meal preparation. The marketing power of large multinational corporations, as well as local companies, has been used effectively to promote their use. ${ }^{1,69}$

Using Monteiro's definition, at least 3 studies have shown positive associations between use of ultraprocessed foods and body weight. ${ }^{70-72}$ In the study of Louzada et al, ${ }^{70}$ Brazilian adolescents and adults within the highest quintile of consumption of ultra-processed foods had a significantly greater BMI $\left(0.94 \mathrm{~kg} / \mathrm{m}^{2}\right.$; $0.42,1.47)$, and a higher odds ratio of being obese (1.98; $1.26,3.12)$ and having increased body weight (1.26; $0.95,1.69)$ compared to those in the lowest quintile of consumption. By contrast, a large cross-sectional study of 2174 adults from the UK investigated associations between body weight and degree of food processing. ${ }^{73}$ They categorized foods into unprocessed or minimally processed, processed ingredients (extracted and purified components of single foods), and ultra-processed foods, the latter being defined as products produced from industrial combining of unprocessed or minimally processed foods and processed ingredients, and found that only a higher intake of extracted purified components of single 
foods was consistently inversely associated with body weight. Their different definition of ultra-processed foods from that of Monteiro could possibly account for the variant results.

The only longitudinal study performed of ultraprocessed foods is that of Mendonca et $\mathrm{al}^{74}$ who followed 8451 middle-aged university graduates for 8.9 years. Adults in the highest quartile for ultra-processed food intake had a significantly higher risk of developing overweight or obesity than those in the lowest quartile. In this study, ultra-processed foods were defined as food and drink products ready to eat, drink or heat and made predominantly or entirely from processed items extracted or refined from whole foods or synthesized in the laboratory and not the definition of Monteiro.

Fardet $^{75}$ examined the satiety and glycemic responses of 98 ready-to-eat foods that were either raw or minimally processed, processed, or ultra-processed using the NOVA classification. A satiety score (available for 38 of these foods) was calculated by dividing the area under the satiety response curve for the test food by the group mean satiety area under the curve for white bread and multiplying by 100. A new glycemic glucose equivalent was also calculated based on the food's glycemic index, \% of available carbohydrate, and food weight consumed. A strong negative correlation was found between the degree of processing and satiety index of these foods $(r=-0.60, p=0.0002)$ and a positive relationship to their glucose glycemic equivalent $\left(\mathrm{r}=0.45, \mathrm{p}=8 \times 10^{6}\right)$, although not their glycemic index.

The demonstration of an increased energy intake of ultra-processed foods in association with decreased satiety could have considerable relevance to portion sizes. It is well documented that food portion sizes in the US have increased from the $1970 \mathrm{~s}$, particularly for energy-dense, ready-to-eat foods. ${ }^{76}$ By 1996, portion sizes for one-third of 107 foods commonly eaten in the US had changed from previous years, with the majority having increased in size, including soft drinks, coffee, tea and ready-to-eat cereals. ${ }^{77}$ Far fewer foods were smaller in serving size.

Ultra-processed foods are also low in fiber. Dietary fiber undergoes partial fermentation by gut bacteria and the short-chain fatty acids produced such as acetate, propionate and butyrate suppress appetite by promoting the release of GLP-1 and peptide YY. ${ }^{78-80}$

Another important aspect of ultra-processed foods is their increased energy density. ${ }^{81}$ Energy density is the amount of energy in a particular weight of food or beverage expressed as calories per gram. The average energy density for ultra-processed foods is twice that of unprocessed foods. ${ }^{82}$ Whether drawn from fat or carbohydrate, a higher energy density leads to increased energy consumption and a long-term increase in body weight. ${ }^{83}$ This is true men and women, overweight and normal weight, children and adults and short term and long term. ${ }^{81}$ People are also usually unaware of differences in energy density and eat a consistent amount of food even when energy density varies from between $25 \%$ and $30 \%$. $^{84-87}$

Forde et al $^{81}$ calculated a measure of energy intake rate (Kcal/min) obtained by combining energy density with eating rate and showed that for 327 foods, energy intake rate increased from $35.5 \pm 4.4$, to $53.7 \pm 4.3$ to $69.4 \pm 3.1$ $\mathrm{kcal} / \mathrm{min}(\mathrm{p}<0.05)$ with unprocessed, to processed, to ultra-processed foods using the definition of Monteiro.

The only interventional study to date on the influence of ultra-processed food on body weight is that of Hall et al ${ }^{88}$ who used the NOVA system definitions and included measurement of eating rate in a cross-over inpatient study comparing an ultra-processed diet with an unprocessed diet. Day 1 breakfasts and lunch for the two groups are shown in the reference section. Adults eating an ad libitum ultra-processed diet for 2 weeks experienced weight gain, whereas 2 weeks of an ad libitum unprocessed diet matched for presented calories, energy density, macronutrients, sugar, sodium and fiber led to weight loss. A significantly increased energy intake with the ultra-processed diet was noted at breakfast $(p=0.008)$ and lunch $(p=0.0003)$, but not at dinner or for snacks. A large difference in eating rate in $\mathrm{kcal} / \mathrm{min}$ was found between the 2 diets $(\mathrm{p}<0.0001)$. There was no difference in "pleasantness" or "familiarity" between the two diets, suggesting that the differences in energy intake were not due to greater palatability or familiarity, and nor were there differences in energy-adjusted scores for hunger, fullness, satisfaction and capacity to eat. Individual differences in average eating rate between the ultra-processed and processed diet were moderately correlated with overall energy intake differences $(r=0.45, \mathrm{p}=0.047)$.

In sum, there is convincing evidence that foods that can be easily eaten because of their texture can lead to a larger bite size, less chewing per gram of food, and decreased meal duration. This in turn can lead to decreased satiation and greater energy intake. Many highly processed foods have this type of texture. Moreover, the soft texture of ultra-processed foods and their resulting low satiation value may have encouraged food manufacturers to manufacture these foods in larger packaging. As a result, 
expectations for what constitutes "normal" food portion sizes have changed.

An influence of ultra-processed foods on energy intake and body weight is very suggestive from cross-sectional and longitudinal studies. In addition, the interventional study of a highly processed diet by Hall et al ${ }^{88}$ supports the notion that an ultra-processed diet leads to more weight gain than a non-processed diet over the short term in association with a change in eating behavior. However, although the presented energy density for the two diets was the same, the energy density of the ultraprocessed diet from non-beverages was almost twice that of the unprocessed diet. Rolls et $\mathrm{al}^{87}$ suggest that beverages, and not only water, influence caloric intake less than solid foods in terms of their energy density, so that an effect of energy density cannot be excluded in this study.

The NOVA system may be a useful one for research, but it is difficult to see how it can be used as an educational tool for the nutritional management of obesity as it is currently defined since its primary focus is on food additives and only indirectly on the aspects of food most relevant to excessive weight gain, namely food texture and energy density. It is also the case that many foods classified as ultra-processed are usually eaten within the context of a meal and it is the overall nature of a diet that likely influences eating behavior and satiation and not individual foods. Nevertheless, it seems very likely that the widespread use of ultra-processed diets could be playing a significant role in the current increase in individual and global obesity.

\section{Persistent Hunger in the Obese}

The papers on oral processing discussed so far, particularly the longitudinal ones, suggest the possibility of a unidirectional relationship between eating behavior, decreased satiation and excessive weight gain. However, new work suggests that the situation may not be as simple as this and that many children and adolescents who are obese may enter into a self-perpetuating cycle of excessive calorie consumption driven by persistent hunger that perpetuates and may even exacerbate the obese state.

In a cross-sectional study of 200 Israeli children and adolescents with obesity and 100 age- and sex-matched normal-weight controls, ratings for hunger, food intake at main meal and speed of eating, and time interval after the main meal of the day to feeling hunger were assessed by means of a questionnaire completed by the parent in cooperation with the child. ${ }^{89}$ The rating for food intake at the main meal of the day was used as an approximate indicator of satiation, and time interval to feeling hunger after the main meal as an approximate indicator of between-meal satiety. The subjects with obesity were recruited from a health-fund weight-control clinic, with obesity being defined as a BMI z-score greater than the 95th percentile for age. Ratings were recorded on 7-point scales. Significant differences between the children with obesity and controls were noted for hunger, speed of eating and satiation $(\mathrm{p}=<0.001)$, and between-meal satiety ( $\mathrm{p}$ $=0.05$ ) after correcting for age and sex. Extreme ratings were apparent in a very high percentage of these children in that the parents of $41 \%$ of the children with obesity admitted to the highest rating for hunger in their offspring ("hungry for most of the time") versus $5 \%$ of non-obese controls ( $p<0.001), 26 \%$ of the offspring had the highest rating for food intake at their main meal of the day ("more than average") versus $0 \%$ of controls ( $p<0.001)$, and $26 \%$ the highest rating for speed of eating ("very fast") versus $4 \%$ of controls $(\mathrm{p}<0.001)$. An abnormal hunger rating of $>4$ (4 being "average") was recorded for $71 \%$ of the children with obesity versus $34 \%$ of the normal-weight children $(\mathrm{p}<0.001), 60 \%$ of the children with obesity had a food intake rating at their main meal greater than normal $(>4)$ compared to $13 \%$ of controls $(p<0.001)$, and $49 \%$ of the children with obesity had a speed of eating rating of $>4$ versus $19 \%$ of controls $(p<0.001)$. These high figures suggest that hunger and abnormal oral processing are extremely common in children with obesity, and confirm results from a similar pediatric study performed in the United States. ${ }^{90}$

As previously discussed, appetite scores have been frequently assessed during experimental manipulations of eating behavior and their correlation with subsequent energy intake has been found to be significant although of low magnitude. ${ }^{4}$ However, the hunger reported on this questionnaire seems to be of a different nature to these satiation scales in that the families are producing an overall assessment of the child's behavior related to hunger and not just hunger sensations. As such it enters into the area of food hedonics, and specifically food wanting, which can be defined as the drive to eat triggered by a food cue. ${ }^{91}$

This type of behavior with intense cravings for food and an inability to reduce food intake has sometimes been considered a form of food addiction in adults with obesity. ${ }^{92,93}$ A review of 19 studies that examined food addiction in adults prior to bariatric surgery found an addiction rate of 14 to $57.8 \%$ using the Yale Food 
Addiction Scale. ${ }^{94}$ The existence of this entity is controversial. Nevertheless, the presence of behavioral issues related to food in adults with morbid obesity would seem to be common. As such, they may be similar, although of a more extreme degree, to the persistent hunger experienced by many of the children with obesity in the pediatric study just quoted.

The food addictive behavior of adults with obesity responds to bowel surgery. In one prospective study, food addiction was present preoperatively among $31.8 \%$ of 44 patients but in only 1 patient within 9 months of bariatric surgery. ${ }^{95}$ Another study found a pre-surgery incidence of food addiction of $57.8 \%$, but only $7.2 \%$ after 6 months and $13.7 \%$ after 12 months. $^{96}$

In sum, the presence of intense and persistent hunger in many individuals with obesity could explain how obesity perpetuates itself and, in many instances, becomes more severe. Cross-sectional studies do not permit determination of etiology. Nevertheless, it is logical to assume that intense and persistent hunger is likely to lead to consequences. It is possible, therefore, that increased hunger can lead to a hedonic desire for more food. This is frequently ultra-processed food that is soft in texture and can be eaten quickly. This may encourage an increase in bite size which in turn may lead to decreased chewing per bite and a decrease in satiation. ${ }^{97}$ On a global level, this could explain why when a population becomes obese there is often a concomitant increase in morbid obesity. ${ }^{2,3}$ The presence of persistent hunger could also explain why obesity in children and adults is so frequently resistant to successful treatment over the long-term.

The mechanism accounting for this type of chronic hunger in the obese is unknown. If food addiction in adults and the chronic hunger described in the pediatric study are indeed one and the same entity, then they should have a common mechanism; in which case, the resolution of food addiction with bariatric surgery would implicate the gut-brain axis. This could be via changes in enteroendocrine secretion, direct vagal stimulation, or changes in the gut microbiota. ${ }^{98-100}$

\section{Changing Eating Behavior in the Obese}

If the hypothesis is correct that changes in eating behavior and the resulting lack of satiation are lynchpins in the development of much obesity, then improving eating behavior should be an effective means for controlling body weight.

Common advice given to individuals with obesity, particularly for those with fast eating, is to slow down their rate of eating, the assumption being that this will decrease caloric intake. Technology that provides feedback on eating rate or food disappearance is now able to convert this advice into treatment protocols. However, several papers suggest reasons why this may have limited success. Spiegel et $\mathrm{al}^{101}$ found that decreasing bite size for sandwiches and bagels pre-cut into different bite size and eaten ad libitum in 9 lean and 9 women with obesity did decrease the average ingestion rate in terms of $\mathrm{g}$ of food eaten per minute $(p=<0.001)$, but this was offset by an increase in meal duration so that meal size did not differ across conditions. There were also no significant differences in hunger or fullness ratings at the end of the meals as a function of bite size. Jasper et $\mathrm{al}^{102}$ found that 94 young adults given a goal for the number of bites to be used for a test meal with feedback from an automated watch-like bite counting device that detected wrist motion were able to reduce the number of bites taken, but subjects compensated for this by taking larger bites, resulting in a comparable level of consumption. Martin et $\mathrm{al}^{103}$ found that slowing individual eating rates for ad libitum test meals in 48 volunteers by means of computer-prompting did reduce food intake for men, but had no effect in women. However, providing the same meal on a small rather than larger plate did reduce intake irrespective of feedback.

A number of long-term controlled trials have been performed in children with obesity attempting to change their eating behavior and hence their energy intake. An 8-week randomized trial in 28 4- to 8-year-old children with obesity compared one group in a program that used a silent vibrating device that vibrated at 30 -second intervals that families were encouraged to use for one meal per day plus 5 sessions providing psychoeducational and behavioral techniques to another group that received only one 30-minute educational session without any behavioral modification and without any device. The vibrating machine group resulted in a parental report of increased slowness in eating $(\mathrm{p}<0.001)$, increased food enjoyment ( $\mathrm{p}$ $=0.004)$, and less BMI gain $\left(0.57 \mathrm{Kg} / \mathrm{m}^{2}, \mathrm{p}=0.02\right) .{ }^{104}$ A 12-month randomized control trial in young people with obesity age 9 to 17 -years by Ford et al $^{105}$ compared standard care provided by a multi-disciplinary team with motivational sessions every 3 months to use of 
a Mandometer device used once a day during a main meal together with multiple training sessions and frequent telephone calls. The Mandometer device has been used in several studies of this nature and consists of a portable weighing scale connected to a portable computer and it provides real-time feedback of food disappearance during meals. The motivational sessions included training on reducing portion size, slowing weight removal from the plate, and normalizing eating rate and satiety responses. After 12-months, main meal size in the Mandometer group fell by $45 \mathrm{~g}(\mathrm{p}=0.061)$, BMI SDS difference was 0.27 (95\% confidence interval $0.14-0.41, \mathrm{p}<0.001$ ), and mean body fat SDS measured by bioimpedance was significantly lower between the two groups. However, there was no significant change in speed of eating or satiety ratings. In a 12 -month study by Galhardo et $\mathrm{al}^{106}$ in 14 adolescents with obesity, the Mandometer device was used for retraining eating behavior in terms of eating at a slower space and helping the participants feel full after consuming 300$350 \mathrm{~g}$ of food over 12-15 minutes, and subjects were instructed to use the device once a day at their main meal of the day. Eating time, portion size, satiety levels and changes in BMI SDS were not significantly different between the participants and 13 controls. However, compared to baseline data, only those using the Mandometer device had significantly lower fasting levels of ghrelin $(\mathrm{p}=$ 0.002 ) and lower mean ghrelin levels under the curve following a glucose load $(\mathrm{p}<0.001)$. The change in absolute suppression of ghrelin at 60 minutes and area under the ghrelin curve were both inversely related to the change in meal duration induced by use of the device. The change in fasting ghrelin was also inversely correlated with the change in pre-meal satiety, and change in area under the ghrelin curve was positively correlated with the change in portion size in the Mandometer group. None of these correlations were seen in the standard treatment group. The 90-minute PYY response was also significantly increased in the Mandometer arm. However, of note is a community pilot randomized controlled trial with the Mandometer device in children with obesity aged 5 to 11 years that was unable to meet any of the criteria for progressing to the main trial. ${ }^{107}$ Only $58 \%$ of families could be recruited, less than $20 \%$ of those randomized to the device used it at least 5 times a week, the $60 \%$ target for slowing down eating speed within 3 months was unmet, and attendance at the weight management clinic was $44 \%$ against a target of $80 \%$.
In conclusion, the results of attempts to change eating behavior have not been particularly successful in terms of producing long-term changes in eating behavior. It also cannot be excluded that positive results obtained with respect to body weight in these studies may be more the result of intensive counselling in the therapeutic group and less to do with any device. In the study of Ford et al, ${ }^{105}$ for example, the therapeutic effort provided to subjects using the Mandometer device and the controls was very unbalanced. This device has also failed to establish itself as a wonder cure for obesity although it has been on the market for a number of years. In fact, most studies with this device are now reported with classic eating disorders.

A number of suggestions can be made as to why interventional studies have been of limited effectiveness. As was demonstrated many years ago, slowing eating in order to decrease energy intake may not always be efficacious, and it is bite size and chewing rate that need to be changed in order to influence satiety. It may be that the Mandometer device is not that effective in doing this. Hence, the study of Ford et $\mathrm{al}^{105}$ showed no long-term effect on speed of eating or satiety, and even the change in portion size did not quite reach significance. It may also be that a more effective way for slowing oral processing is by changing the texture of the diet. The influence of chronic hunger may also override attempts to change eating behavior if untreated. This could be why individuals with marked changes in oral processing may be the most resistant to slowing their eating behavior with monitoring and the least likely to use this type of therapy conscientiously. ${ }^{107}$

\section{Conclusion}

From the topics discussed it is possible to propose the following scheme to explain how individual and global obesity develops in many people and how it perpetuates itself. An important factor is inadequate satiation, or an inability to appropriately terminate a meal, and this results in overeating. For many people, this is dietrelated and due to the consumption of a predominance of soft-textured foods, and in particular highly processed solid foods, semi-solid desserts and high-calorie drinks. These foods are frequently associated with a large bite or sip size and inadequate oral processing due to reduced chewing of each bite. This can often be appreciated by the individual and/or observer as an increased speed of eating. There may well be a genetic influence to this progression. The poor satiation associated with highly 
processed foods has encouraged food manufacturers to package their products in larger packaging and this has led to new perceptions of what constitutes a normal portion size for these items. Ultra-processed foods also have a high energy density due to their content of sugar and fat and this can also lead to an increased caloric intake. ${ }^{81,87}$

At a certain stage in the development of obesity, many individuals with obesity develop persistent hunger, although so far this has only been demonstrated in children. The etiology of this is unknown, but is likely related to changes in the gut-brain axis. When severe, it is likely to compound an obesity problem by increasing preexisting eating abnormalities and thereby setting up a vicious cycle (see Figure 1). The relative importance of these three etiological factors abnormal oral processing, increased energy density and persistent hunger in increasing caloric intake over the short and long term is unclear, although this is clearly a question of considerable importance.

Despite this lack, Figure 1 can be useful for planning treatment strategies and understanding why certain strategies may have limited long-term effectiveness on obesity prevention and treatment. This includes, for example, a focus on energy density without attention to oral processing and persistent hunger. Cutting back on total food intake may also exacerbate preexisting chronic hunger.

This figure also highlights why new paradigms for the treatment and prevention of obesity are needed in terms of changing the inappropriate nutrition, inappropriate oral processing, and persistent hunger that typifies many individuals with obesity. ${ }^{79}$ Highly processed foods seem to

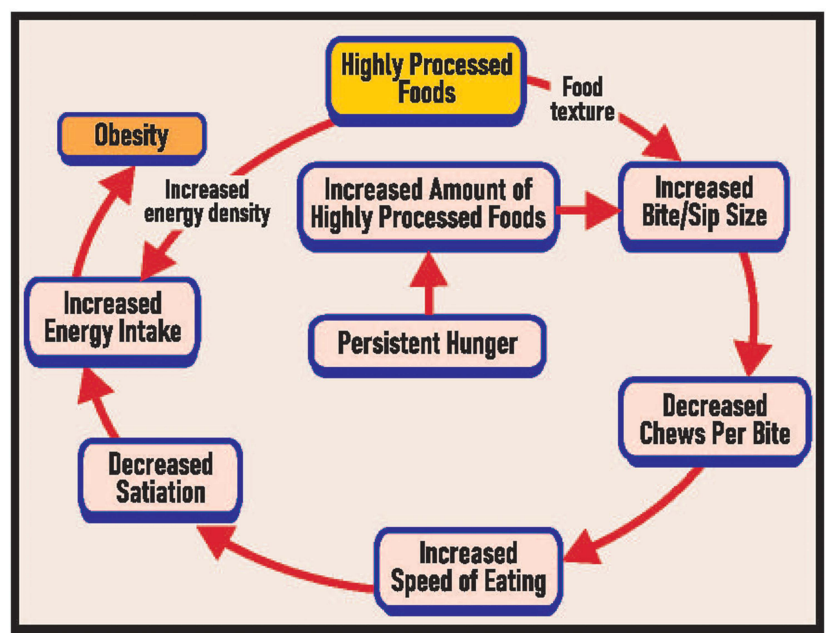

Figure I Hypothesized scheme for the associations between highly processed foods, oral processing, energy density, persistent hunger and obesity. have a major role in the initiation of these disturbances. However, most would agree that there is no going backwards in the use of these foods because of their overall usefulness. Nevertheless, there is good reason to discourage diets containing a predominance of ultra-processed foods and to encourage other diets in their stead that could be more effective in preventing and treating obesity. ${ }^{108}$

\section{Disclosure}

The author Arnold Slyper, MD states that no competing financial interests exist to the work described. The author is not in receipt of any specific grants from funding agencies in the public, commercial, or not-for-profit sectors.

\section{References}

1. Global Panel on Agriculture and Food Systems for Nutrition. Food systems and diets: facing the challenges of the 21st century. London: Global Panel. Pan American Health Organization of the World Health; 2016. Available from: http:// glopan.org/sites/default/files/ForesightReport.pdf. Accessed July 19, 2021.

2. Bambs C, Cerda J, Escalonac A. Morbid obesity in a developing country: the Chilean experience. Bull World Health Organ. 2008;86:813-814. doi:10.2471/BLT.07.048785

3. Zhang Y-X, Chu Z-H, Li S-Y, Zhao J-S, Zhou J-Y. Trends in the prevalence of morbid obesity among children and adolescents in Shandong, China, 1995-2014. J Trop Pediatr. 2018;64:60-66. doi:10.1093/tropej/fmx030

4. Sadoul BC, Schuring EA, Mela DJ, Peters HP. The relationship between appetite scores and subsequent energy intake: an analysis based on 23 randomized controlled studies. Appetite. 2014;83:153-159. doi:10.1016/j.appet.2014.08.016

5. Farooq M, Sazonov E. Automatic measurement of chew count and chewing rate during food intake. Electronics (Basel). 2016;5 (4). doi:10.3390/electronics5040062

6. McCrickerd K, Forde CG. Consistency of eating rate, oral processing behaviours and energy intake across meals. Nutrients. 2017;9(8):891. doi:10.3390/nu9080891

7. Forde CG, van Kuijk N, Thaler T, de Graaf C, Martin N. Oral processing characteristics of sold savoury meal components, and relationship with food composition, sensory attributes and expected satiation. Appetite. 2013;60:208-219. doi:10.1016/j. appet.2012.09.015

8. Doulah A, Yang X, Parton J, Higgins JA, McCrory MA, Sazonov E. The importance of field experiments in testing of sensors for dietary assessment and eating behavior monitoring. 2018 40th Annual International Conference of the IEEE Engineering in Medicine and Biology Society (EMBC); 2018:5759-5762. doi: 10.1109/EMBC.2018.8513623.

9. Zijlstra N, Bukman AJ, Mars M, Stafleu A, Ruijschop RM, de Graaf C. Eating behaviour and retro-nasal aroma release in normal-weight and overweight adults: a pilot study. $\mathrm{Br} J \mathrm{Nutr}$. 2011;106:297-306. doi:10.1017/S0007114511000146

10. Hill SW, McCutcheon NB. Contributions of obesity, gender, hunger, food preference, and body size to bite size, bite speed, and rate of eating. Appetite. 1984;5:73-83. doi:10.1016/S01956663(84)80026-4

11. Kissileff HR, Thornton J, Becker E. A quadratic equation adequately describes the cumulative food intake curve in man. Appetite. 1982;3:255-272. doi:10.1016/S0195-6663(82)80022-6 
12. Barkeling B, Rössner S, Sjöberg A. Methodological studies on single meal food intake characteristics in normal weight and obese men and women. Int $J$ Obes Relat Metab Disord. 1995;19:284-290.

13. Laessle RG, Lehrke S, Dückers S. Laboratory eating behavior in obesity. Appetite. 2007;49:399-404. doi:10.1016/j.appet.2006.1 1.010

14. Cecil JE, Francis J, Read NW. Relative contributions of intestinal, gastric, oro-sensory influences and information to changes in appetite induced by the same liquid meal. Appetite. 1998;31:377-390. doi:10.1006/appe.1998.0177

15. French SJ, Cecil JE. Oral, gastric and intestinal influences on human feeding. Physiol Behav. 2001;74:729-734. doi:10.1016/ S0031-9384(01)00617-5

16. Cecil JE, Francis J, Read NW. Comparison of the effects of a high-fat and high-carbohydrate soup delivered orally and intragastrically on gastric emptying, appetite, and eating behavior. Physiol Behav. 1999;67:299-306. doi:10.1016/S0031-9384(99) 00069-4

17. Robinson E, Almiron-Roig E, Rutters F, et al. A systematic review and meta-analysis examining the effect of eating rate on energy intake and hunger. Am J Clin Nutr. 2014;100:123-151. doi:10.3945/ajen.113.081745

18. Krop EM, Hetherington MM, Nekitsing C, Miquel S, Postelnicu L, Sarkar A. Influence of oral processing on appetite and food intake - a systematic review and meta-analysis. Appetite. 2018;125:253-269. doi:10.1016/j.appet.2018.01.018

19. Miquel-Kergoat S, Azais-Braesco V, Burton-Freeman B, Hetherington NM. Effects of chewing on appetite, food intake and gut hormones: a systematic review and meta-analysis. Physiol Behav. 2015;151:88-96. doi:10.1016/j.physbeh.2015.07.017

20. Hameed S, Dhillo WS, Bloom SR. Gut hormones and appetite control. Oral Dis. 2009;15:18-26. doi:10.1111/j.16010825.2008.01492.x

21. Kokkinos A, le Roux CW, Alexiadou K, et al. Eating slowly increases the postprandial response of the anorexigenic gut hormones, peptide YY and glucagon-like peptide-1. J Clin Endocrinol Metab. 2010;95:333-337. doi:10.1210/jc.2009-1018

22. Rigamonti AE, Agosti F, Compri E, et al. Anorexigenic postprandial responses of PYY and GLP1 to slow ice cream consumption: preservation in obese adolescents, but not in obese adults. Eur $J$ Endocrinol. 2013;168:429-436. doi:10.1530/EJE-12-0867

23. Zhu Y, Hsu WH, Hollis JH. Increasing the number of masticatory cycles is associated with reduced appetite and altered postprandial plasma concentrations of gut hormones, insulin and glucose. $\mathrm{Br}$ $J$ Nutr. 2013;110:384-390. doi:10.1017/S0007114512005053

24. Cassady BA, Hollis JH, Fulford AD, Considine RV, Mattes RD. Mastication of almonds: effects of lipid bioaccessibility, appetite, and hormone response. Am J Clin Nutr. 2009;89:794-800. doi:10.3945/ajen.2008.26669

25. Hawton K, Ferriday D, Rogers P, et al. Slow down: behavioural and physiological effects of reducing eating rate. Nutrients. 2018;11(1):50. doi:10.3390/nu11010050

26. Alsalim W, Ahren B. Insulin and incretin hormone responses to rapid versus slow ingestion of a standardized solid breakfast in healthy subjects. Endocrinol Diabetes Metab. 2019;2(2):e00056. doi:10.1002/edm2.56

27. Shah M, Crisp K, Adams-Huet B, et al. The effect of eating speed at breakfast on appetite hormone responses and daily food consumption. J Invest Med. 2015;63:22-28. doi:10.1097/ JIM.0000000000000119

28. Ohkuma T, Hirakawa Y, Nakamura U, Kiyohara Y, Kitazono T, Ninomiya T. Association between eating rate and obesity: a systematic review and meta-analysis. Int $J$ Obes (Lond). 2015;39:1589-1596. doi:10.1038/ijo.2015.96
29. Leong SL, Madden C, Gray A, Waters D, Horwath C. Faster self-reported speed of eating is related to higher body mass index in a nationwide survey of middle-aged women. $J$ Am Diet Assoc. 2011;111:1192-1197. doi:10.1016/j.jada.2011.05.012

30. Liu S, Zhang J, Ma J, et al. Synergistic interaction between bedtime and eating speed in predicting overweight and obesity in Chinese preschool-aged children. Aging. 2019;11:2127-2137. doi:10.18632/aging.101906

31. Lin M, Pan L, Tang L, Jiang J, Wang Y, Jin R. Association of eating speed and energy intake of main meals with overweight in Chinese pre-school children. Public Health Nutr. 2014;17:2029-2036. doi:10.1017/S1368980013002176

32. Zhang T, Cai L, Ma L, Jing J, Chen Y, Ma J. The prevalence of obesity and influence of early life and behavioral factors on obesity in Chinese children in Guangzhou. BMC Public Health. 2016;16:954. doi:10.1186/s12889-016-3599-3

33. Zeng X, Cai L, Ma J, Ma Y, Jing J, Chen Y. Eating fast is positively associated with general and abdominal obesity among Chinese children: a national survey. Sci Rep. 2018;8:14362. doi:10.1038/s41598-018-32498-9

34. Ochiai H, Shirasawa T, Ohtsu T, et al. Eating behaviors and overweight among adolescents: a population-based survey in Japan. J Obes. 2013:717942. doi:10.1155/2013/717942

35. Ochiai $H$, Shirasawa $T$, Ohtsu $T$, et al. The impact of eating quickly on anthropometric variables among schoolgirls: a prospective cohort study in Japan. Eur J Public Health. 2014;24:691-695. doi:10.1093/eurpub/ckt120

36. Yamagishi K, Sairenchi T, Sawada N, et al. Impact of speedeating habit on subsequent body mass index and blood pressure among school children - the Ibaraki Children's Cohort Study (IBACHIL). Circ J. 2018;82:419-422. doi:10.1253/circj.CJ-170287

37. Ochiai H, Shirasawa T, Nanri H, Nishimura R, Hoshino H, Kokaze A. Relationship between eating quickly and overweight: a Cohort Study of school children in Japan. Acta Med Okayama. 2018;72:121-128. doi:10.18926/AMO/55852

38. Yamane M, Ekuni D, Mizutani S, et al. Relationships between eating quickly and weight gain in Japanese university students a longitudinal study. Obesity. 2014;22:2262-2266. doi:10.1002/ oby. 20842

39. Tanihara S, Imatoh T, Miyazaki M, et al. Retrospective longitudinal study on the relationship between 8-year weight change and current eating speed. Appetite. 2011;57:179-183. doi:10.1016/j.appet.2011.04.017

40. Hamada Y, Miyaji A, Hayashi Y, Matsumoto N, Nishiwaki M, Hayashi N. Objective and subjective eating speeds are related to body composition and shape in female college students. $J$ Nutr Sci Vitaminol. 2017;63:174-179. doi:10.3177/jnsv.63.174

41. Sun Y, Sekine M, Kagamimori S. Lifestyle and overweight among Japanese adolescents: the Toyama Birth Cohort Study. J Epidemiol. 2009;19:303-310. doi:10.2188/jea.JE20080095

42. Fogel A, Goh AT, Fries LR, et al. Faster eating rates are associated with higher energy intakes during an ad libitum meal, higher BMI and greater adiposity among $4 \cdot 5$-year-old children: results from the Growing Up in Singapore Towards Healthy Outcomes (GUSTO) cohort. Br J Nutr. 2017;117:1042-1051. doi:10.1017/S0007114517000848

43. Wagner M, Hewitt MI. Oral satiety in the obese and nonobese. $J$ Am Diet Assoc. 1975;67:344-346.

44. Mattfeld RS, Muth ER, Hoover A. Measuring the consumption of individual solid and liquid bites using a table-embedded scale during unrestricted eating. IEEE $J$ Biomed Health Inform. 2017;21:1711-1718. doi:10.1109/JBHI.2016.2632621

45. Zijlstra N, de Wijk RA, Mars M, Stafleu A, De Graaf C. Effect of bite size and oral processing time of a semisolid food on satiation. Am J Clin Nutr. 2009;90:269-275. doi:10.3945/ajcn.2009.27694 
46. Weijzen PLG, Smeets PAM, de Graaf C. Sip size of orangeade: effects on intake and sensory-specific satiation. $\mathrm{Br} J$ Nutr. 2009;102:1091-1097. doi:10.1017/S000711450932574X

47. Forde CG, Fogel A, McCrickerd K. Children's eating behaviors and energy intake: overlapping influences and opportunities for intervention. Nestle Nutr Inst Workshop Ser. 2019;91:55-67. doi:10.1159/000493695

48. Goto T, Nakamich A, Watanabe M, Nagao K, Matsuyama M, Ichikawa T. Influence of food volume per mouthful on chewing and bolus properties. Physiol Behav. 2015;141:58-62. doi:10.1016/j.physbeh.2015.01.007

49. Berkowitz RI, Moore RH, Faith MS, Stallings VA, Kral TV, Stunkard AJ. Identification of an obese eating style in 4-yearold children born at high and low risk for obesity. Obesity (Silver Spring). 2010;18:505-512. doi:10.1038/oby.2009.299

50. Llewellyn $\mathrm{CH}$, van Jaarsveld $\mathrm{CH}$, Boniface $\mathrm{D}$, Carnell $\mathrm{S}$, Wardle J. Eating rate is a heritable phenotype related to weight in children. Am J Clin Nutr. 2008;88:1560-1566. doi:10.3945/ ajen.2008.26175

51. Toyama K, Zhao X, Kuranuki S, et al. The effect of fast eating on the thermic effect of food in young Japanese women. Int J Food Sci Nutr. 2015;66:140-147. doi:10.3109/09637486.2014.986069

52. Komai N, Motokubota N, Suzuki M, Hayashi I, Mortani T, Nagai N. Thorough mastication prior to swallowing increases postprandial satiety and the thermic effect of a meal in young women. J Nutr Sci Vitaminol (Tokyo). 2016;62:288-294. doi:10.3177/jnsv.62.288

53. Levine J, Baukol P, Pavlidis I. The energy expended in chewing gum. N Engl J Med. 1999;341:2100. doi:10.1056/NEJM1999123 03412718

54. Brondel L, Fricker J, Fantinol M. Postprandial thermogenesis and alimentary sensory stimulation in human subjects. Int $J$ Obes. 1999;23:34-40. doi:10.1038/sj.ijo.0800754

55. Granata GP, Brandon LJ. The thermic effect of food and obesity: discrepant results and methodological variations. Nutr Rev. 2002;60:223-233. doi:10.1301/002966402320289359

56. de Jonge L, Bray GA. The thermic effect of food and obesity: a critical review. Obes Res. 1997;5:622-631. doi:10.1002/j.15508528.1997.tb00584.x

57. McCrickerd K, Forde CG. Sensory influences on food intake control: moving beyond palatability. Obes Rev. 2016;17:18-29. doi:10.1111/obr.12340

58. de Graaf C, Kok FJ. Slow food, fast food and the control of food intake. Nat Rev Endocrinol. 2010;6:290-293. doi:10.1038/ nrendo.2010.41

59. Zijlstra N, Mars M, de Wijk RA, Westerterp-Plantenga MS, de Graaf $\mathrm{C}$. The effect of viscosity on ad libitum food intake. Int J Obes (Lond). 2008;32:676-683. doi:10.1038/sj.ijo.0803776

60. Forde CG, van Kuijk N, Thaler T, de Graaf C, Martin N. Texture and savoury taste influences on food intake in a realistic hot lunch time meal. Appetite. 2013;60:180-186. doi:10.1016/j. appet.2012.10.002

61. Lasschuijt MP, Mars M, Stieger M, Miquel-Kergoat S, de Graaf C, Smeets PAM. Comparison of oro-sensory exposure duration and intensity manipulations on satiation. Physiol Behav. 2017;176:76-83. doi:10.1016/j.physbeh.2017.02.003

62. Bolhuis DP, Forde CG, Cheng Y, Xu H, Martin N, de Graaf C. Slow food: sustained impact of harder foods on the reduction in energy intake over the course of the day. PLoS One. 2014;9:1-7. doi:10.1371/journal.pone.0093370

63. Mosca AC, Torres AP, Slob E, de Graaf K, McEwan JA, Stieger M. Small food texture modications can be used to change oral processing behavior and to control ad libitum food intake. Appetite. 2019;142:104375. doi:10.1016/j.appet.2019.104375
64. Larsen DS, Tang J, Ferguson LR, James BJ. Increased textural complexity in food enhances satiation. Appetite. 2016;105:189-194. doi:10.1016/j.appet.2016.05.029

65. Bolhuis DP, Lakemond CM, de Wijk RA, Luning PA, Graaf C. Both longer oral sensory exposure to and higher intensity of saltiness decrease ad libitum food intake in healthy normal-weight men. J Nutr. 2011;141:2242-2248. doi:10.3945/ jn. 111.143867

66. van den Boer J, Werts M, Siebelink E, De graaf C, Mars M. The availability of slow and fast calories in the Dutch diet: the current situation and opportunities for interventions. Foods. 2017;6 (10):87. doi:10.3390/foods6100087

67. Martínez Steele E, Baraldi LG, Louzada ML, Moubarac JC, Mozaffarian D, Monteiro CA. Ultra-processed foods and added sugars in the US diet: evidence from a nationally representative cross-sectional study. BMJ Open. 2016;6(3):e009892. doi:10.1136/bmjopen-2015-009892

68. Monteiro CA, Cannon G, Levy RB, et al. Ultra-processed foods: what they are and how to identify them. Public Health Nutr. 2019;22:936-941. doi:10.1017/S1368980018003762

69. Gibney MJ, Forde CG, Mullally D, Gibney ER. Ultra-processed foods in human health: a critical appraisal. Am J Clin Nutr. 2017;106:717-724.

70. Louzada ML, Baraldi LG, Steele EM, et al. Consumption of ultra-processed foods and obesity in Brazilian adolescents and adults. Prev Med. 2015;81:9-15. doi:10.1016/j.ypmed.20 15.07.018

71. Monteiro CA, Moubarac JC, Levy RB, Canella DS, Louzada MLDC, Cannon G. Household availability of ultra-processed foods and obesity in nineteen European countries. Public Health Nutr. 2018;21:18-26. doi:10.1017/ S1368980017001379

72. Cannon G, Levy R, Moubarac J-C, et al. Food classification. Public Health-NOVA. The star shines bright. World Nutr. 2016;7:23-38.

73. Adams J, White M. Characterisation of UK diets according to degree of food processing and associations with sociodemographics and obesity: cross-sectional analysis of UK National Diet and Nutrition Survey (2008-12). Int J Behav Nutr Phys Act. 2015;12:160. doi:10.1186/s12966-015-0317-y

74. Mendonca RD, Pimenta AM, Gea A, et al. Ultraprocessed food consumption and risk of overweight and obesity: the University of Navarra Follow-Up (SUN) cohort study. Am J Clin Nutr. 2016;104:1433-1440. doi:10.3945/ajcn.116.135004

75. Fardet A. Minimally processed foods are more satiating and less hyperglycemic than ultra-processed foods: a preliminary study with 98 ready-to-eat foods. Food Funct. 2016;7:2338-2346. doi:10.1039/c6fo00107f

76. Young LR, Nestle M. The contribution of expanding sizes to the US obesity epidemic. Am J Public Health. 2002;92:246-249. doi:10.2105/AJPH.92.2.246

77. Smiciklas-Wright H, Mitchell DC, Mickle SJ, Goldman JD, Cook A. Foods commonly eaten in the United States, 19891991 and 1994-1996. Are portion sizes changing? J Am Diet Assoc. 2003;103:41-44. doi:10.1053/jada.2003.50000

78. Kaji I, Karaki S, Kuwahara A. Short-chain fatty acid receptor and its contribution to glucagon-like peptide-1 release. Digestion. 2014;89(1):31-36. doi:10.1159/000356211

79. Slyper AH. A paradigm shift for the prevention and treatment of individual and global obesity. Diabetes Metab Syndr Obes. 2018;11:855-861. doi:10.2147/DMSO.S183777

80. Edwin E, Martínez L, Maira R, Campos S. Effect of ultra-processed diet on gut microbiota and thus its role in neurodegenerative diseases. Nutrition. 2020;71:1100609. doi:10.1016/j. nut.2019.110609 
81. Forde CG, Mars M, de Graaf K. Ultra-processing or oral processing? A role for energy density and eating rate in moderating energy intake from processed foods. Curr Dev Nutr. 2020;4: nzaa019. doi:10.1093/cdn/nzaa019

82. Gupta S, Hawk T, Aggarwal A, Drewnowski A. Characterizing ultra-processed foods by energy density, nutrient density, and cost. Front Nutr. 2019;6:70. doi:10.3389/fnut.2019.00070

83. Rolls BJ, Bell EA, Castellanos VH, Chow M, Pelkman CI, Thorwart ML. Energy density but not fat content of foods affected energy intake in lean and obese women. Am J Clin Nutr. 1999;69:863-871. doi:10.1093/ajcn/69.5.863

84. Leahy KF, Birch LL, Rolls BJ. Reducing the energy density of an entrée decreases children's energy intake at lunch. $J$ Am Diet Assoc. 2008;108:41-48. doi:10.1016/j.jada.2007.10.015

85. Blatt AD, Roe LS, Rolls BJ. Hidden vegetables: an effective strategy to reduce energy intake and increase vegetable intake in adults. Am J Clin Nutr. 2011;93:756-763. doi:10.3945/ ajen.110.009332

86. Smethers AD, Roe LS, Sanchez CE, Zuraikat FM, Keller KL, Rolls BJ. Both increases and decreases in energy density lead to sustained changes in preschool children's energy intake over 5 days. Physiol Behav. 2019;204:210-218. doi:10.1016/j. physbeh.2019.02.042

87. Rolls BJ, Cunningham PM, Diktas HE. Properties of ultraprocessed foods that can drive excess intake. Nutr Today. 2020;55:109-115. doi:10.1097/NT.0000000000000410

88. Hall KD, Ayuketah A, Brychta R, et al. Ultra-processed diets cause excess calorie intake and weight gain: an Inpatient Randomized Controlled Trial of Ad Libitum Food Intake. Cell Metab. 2019;30:67-77.e3.. doi:10.1016/j.cmet.2019.05.008 (Breakfast on the ultra-processed diet on day 1 was Honey Nut Cheerios, whole milk with NutriSource fiber and a blueberry muffin. Lunch was beef ravioli, Parmesan cheese, white bread, diet lemonade with NutriSource fiber and oatmeal raisin cookies. The non-processed breakfast on day 1 was Greek yogurt parfait with strawberries, bananas, and walnuts, olive oil, apple slices with fresh squeezed lemon, and for lunch spinach salad with chicken breast, apple slices, bulgur, sunflower seeds and grapes and vinaigrette)

89. Slyper AH, Shenker J, Israel A. A questionnaire-based assessment of hunger, speed of eating and food intake in children with obesity. Diabetes Metab Syndr Obes. 2021;14:59-66. doi:10.2147/DMSO.S286291

90. Slyper AH, Kopfer K, Huang W-M, Re'em Y. Increased hunger and speed of eating in obese children and adolescents. $J$ Pediatr Endocrinol Metab. 2014;27:413-417. doi:10.1515/jpem-20130271

91. Gibbons C, Hopkins M, Beaulieu K, Oustric P, Blundell JE. Issues in measuring and interpreting human appetite (satiety/ satiation) and its contribution to obesity. Curr Obes Rep. 2019;8:77-87. Review. doi:10.1007/s13679-019-00340-6

92. Schulte EM, Avena NM, Gearhardt AN. Which foods may be addictive? The roles of processing, fat content, and glycemic load. PLoS One. 2015;10(2):e0117959. doi:10.1371/journal. pone. 0117959

93. Lennerz B, Lennerz JK. Food addiction, high glycemic carbohydrates and obesity. Clin Chem. 2018;64:64-71. doi:10.1373/ clinchem.2017.273532
94. Ivezaj V, Wiedemann AA, Grilo CM. Food addiction and bariatric surgery: a systemic review of the literature. Obes Rev. 2017;18:1386-1397. doi:10.1111/obr.12600

95. Pepino MY, Stein RI, Eagon JC, Klein S. Bariatric surgery-induced weight loss causes remission of food addiction in extreme obesity. Obesity. 2014;22:1792-1798. doi:10.1002/ oby. 20797

96. Sevincer GM, Konuk N, Bozkurt S, Coskun H. Food addiction and the outcome of bariatric surgery at 1-year: prospective observational study. Psychiatry Res. 2016;244:159-164. doi:10.1016/j. psychres.2016.07.022

97. Almiron-Roig E, Tsiountsioura M, Lewis HB, Wu J, SolisTrapala I, Jebb SA. Large portion sizes increase bite size and eating rate in overweight women. Physiol Behav. 2015;139:297-302. doi:10.1016/j.physbeh.2014.11.041

98. Hutch CR, Sandoval D. The role of GLP-1 in the metabolic success of bariatric surgery. Endocrinology. 2017;158:4139-4151. doi:10.1210/en.2017-00564

99. Salehi M, D'Alessio DA. Mechanisms of surgical control of type 2 diabetes: GLP-1 is the key factor - maybe. Surg Obes Relat Dis. 2016;12:1230-1235. doi:10.1016/j.soard.2016.05.008

100. Magouliotis DE, Tasiopoulou VS, Sioka E, Chatedaki C, Zacharoulis D. Impact of bariatric surgery on metabolic and gut microbiota profile: a systemic review and meta-analysis. Obes Surg. 2017;27:1345-1357. doi:10.1007/s11695-017-2595-8

101. Spiegel TA, Kaplan JM, Tomassini A, Stellar E. Bite size, ingestion rate, and meal size in lean and obese women. Appetite. 1993;21:131-145. doi:10.1016/0195-6663(93)90005-5

102. Jasper PW, James MT, Hoover AW, Muth ER. Effects of bite count feedback from a wearable device and goal setting on consumption in young adults. $J$ Acad Nutr Diet. 2016;116:1785-1793. doi:10.1016/j.jand.2016.05.004

103. Martin CK, Anton SD, Walden H, Arnett C, Greenway FL, Williamson DA. Slower eating rate reduces the food intake of men, but not women: implications for behavioral weight control. Behav Res Ther. 2007;45:2349-2359. doi:10.1016/j. brat.2007.03.016

104. Faith MS, Diewald LK, Crabbe S, Burgess B, Berkowitz RI. Reduced eating pace (RePace) behavioral intervention for children prone to or with obesity: does the Turtle Win the Race? Obesity (Silver Spring). 2019;27:121-129. doi:10.1002/ oby. 22329

105. Ford AL, Bergh C, Södersten P, et al. Treatment of childhood obesity by retraining eating behaviour: randomised controlled trial. BMJ. 2009;340:b5388. doi:10.1136/bmj.b5388

106. Galhardo J, Hunt LP, Lightman SL, et al. Normalizing eating behavior reduces body weight and improves gastrointestinal hormonal secretion in obese adolescents. J Clin Endocrinol Metab. 2012;97:E193-201. doi:10.1210/jc.2011-1999

107. Julian Hamilton-Shield J, Goodred J, Powell L, et al. Changing eating behaviours to treat childhood obesity in the community using Mandolean: the Community Mandolean randomised controlled trial (ComMando)-a pilot study. Health Technol Assess. 2014;18(47):i-xxiii, 1-75. doi:10.3310/hta18470

108. Yannakoulia M, Aggelopoulou D, Skenderi K, Koinaki S, Yiannakouris N. A Mediterranean-like breakfast affects energy intake and appetite-related feelings. Int $J$ Food Sci Nutr. 2014;65:899-902. doi:10.3109/09637486.2014.931359 


\section{Publish your work in this journal}

Diabetes, Metabolic Syndrome and Obesity: Targets and Therapy is an international, peer-reviewed open-access journal committed to the rapid publication of the latest laboratory and clinical findings in the fields of diabetes, metabolic syndrome and obesity research. Original research, review, case reports, hypothesis formation, expert opinion and commentaries are all considered for publication. The manuscript management system is completely online and includes a very quick and fair peer-review system, which is all easy to use. Visit http://www.dovepress.com/testimonials.php to read real quotes from published authors.

Submit your manuscript here: https://www.dovepress.com/diabetes-metabolic-syndrome-and-obesity-targets-and-therapy-journal 